\title{
BRITTO, PAulo HenriQues. A TraduÇão literária. Rio de JANEIRO: CIVILIZAÇÃO BRASILEIRA, 2012.157P.
}

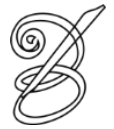 \\ Giovana Bleyer Ferreira dos Santos ${ }^{1}$ \\ (Doutoranda - PGET/UFSC-Florianópolis/SC/Brasil) \\ giovanableyer@gmail.com
}

tradução literária traz, em três capítulos, uma concisa discussão sobre a tradução
de textos literários, mais especificamente de ficção e poesia, pautada em
importantes aspectos que caracterizam essa atividade.

No primeiro capítulo, “Algumas considerações gerais”, Paulo Henriques Britto discorre sobre pontos que, embora devessem ser de conhecimento geral, muitas vezes parecem ficar esquecidos, como o fato de muitas pessoas dependerem indiretamente de traduções, seja para ler um livro, um manual, assistir a um filme estrangeiro, o que valida a tradução como uma atividade indispensável nos dias de hoje.

Tendo melhor se constituído como um campo de estudos a partir da década de 1970, como destaca o autor, diversas reflexões sobre a atividade tradutória têm surgido e mecanismos têm sido desenvolvidos para viabilizar alguns setores que dependem dessa atividade. É o caso mencionado por Britto (2012) de programas que automatizam a tradução de certo tipo de textos, mas que, mesmo facilitando essa passagem de texto de um idioma para outro, não são eficientes o suficiente para dispensarem a boa e velha interferência humana que, nesse caso, é feita por um profissional, que busca dar coerência ao produto final, o texto traduzido. Esse profissional, denominado tradutor, passa por uma série de problemas e, buscando realizar seu trabalho pautado em uma ética, deve procurar sempre refletir sobre suas escolhas e as implicações que elas podem gerar no texto de chegada. E, para que seja possível realizar um bom trabalho, o autor destaca pensamentos que devem estar consolidados na formação deste tradutor, mais especificamente no tradutor literário, para que após concluir sua tradução ele possa de fato olhá-la e acreditar que ela tem todas as exigências que permitem que um leitor, desconhecendo o idioma da obra que originou aquela tradução, possa de fato dizer que leu determinada obra, quando por sua vez tiver lido a tradução daquela obra. Para 
que isto ocorra o tradutor deve seguir as regras que Britto (2012, p. 28) denomina "jogo da tradução".

Em linhas gerais Britto (2012) distingue três princípios que o guiam em sua exposição sobre o que o tradutor deve considerar para entrar no "jogo das traduções":

\begin{abstract}
A ausência de certeza absoluta não é a mesma coisa que a incerteza absoluta; todas as classificações são imprecisas [...] mas a imprecisão não implica a sua inutilidade; o fato de sermos obrigados a relativizar a possibilidade de atingir uma meta não implica que devamos negar a possibilidade de se adotar essa meta (BRITTO, 2012, p. 29-30).
\end{abstract}

Estes princípios expostos pelo autor surgem a partir de uma reflexão geral sobre o texto, especialmente o literário, de sua experiência como tradutor e da análise de traduções.

Britto (2012) nos faz recordar que um texto possui diferentes possibilidades de leitura e que esta característica é um dos fatores que confere um maior ou menor grau de dificuldade à tradução de determinada obra. Além disso, o autor também destaca que um texto está inserido dentro de uma cultura. Ele é uma representação de um tempo, de um espaço e traz consigo marcas que permitem que ele seja classificado em um determinado lugar na história.

230 A tarefa do tradutor é tanto procurar transpor para o texto de chegada elementos representativos da cultura a que pertence seu texto de partida quanto manter características que singularizam a produção textual daquele autor que ele está traduzindo. Estes fatores tornam desejável que o tradutor conheça muito bem o autor e a obra que está traduzindo e que ele tenha como meta inserir em sua tradução todas as marcas que singularizam seu texto de partida. Com isso, voltamos aos princípios mencionados por Britto (2012) que nos levam a considerar que: ainda que não seja possível transpor todas as marcas do texto de partida para o texto de chegada, é aconselhável que sejam estabelecidas classificações sobre o que deve ser recriado no texto de chegada; e mesmo que saibamos que é impossível que a tradução contenha cem por cento das marcas do texto de partida, por questões que se pautam por exemplo na própria diferença entre as línguas, suas estruturas sintáticas, suas formas de significação, isso não quer dizer que o tradutor não deva ter como objetivo alcançar essa meta. A tradução pensada desta maneira permitirá que o leitor da tradução possa confiar no texto lido e que ao dizer que leu determinado autor, ainda que tenha sido por meio da tradução de sua obra, haja verdade nesta declaração, visto que o texto de chegada foi construído mantendo-se todas as marcas possíveis do texto de partida e que por isso há correspondência entre eles. Aqui é válido mencionarmos ainda que o autor vê a escritura de paratextos (prefácios, posfácios, notas de rodapé) como recurso auxiliar na transposição destas marcas 
que caracterizam determinada obra, autor, cultura e momento histórico para o texto de chegada.

Partindo-se para o segundo capítulo, "A tradução de ficção", o autor retoma a dicotomia mencionada por Schleiermacher, sobre o tradutor ter duas opções ao realizar seu trabalho, a de domesticar o texto ou estrangeirizá-lo, e contrapõe-se a ela dizendo que sua experiência de tradutor o ensinou que é preciso tomar uma posição intermediária e que o "que vai determinar o grau de estrangeirização e de domesticação adotado é uma série de valores" (BRITTO, 2012, p. 63) dos quais ele apresenta três. Se o autor a ser traduzido tiver um grande prestígio e sua obra for marcada por singularidades de estilo, de linguagem, a tendência é que ocorra uma tradução mais estrangeirizadora, visto que o tradutor procurar reproduzir estas características no texto de chegada. Se o público-alvo tiver uma menor "sofisticação intelectual" (BRITTO, 2012, p. 64), como é o caso do público infanto-juvenil, o tradutor precisará adotar algumas estratégias domesticadoras para evitar, por exemplo, que possíveis dificuldades de leitura desviem o leitor do texto. E o terceiro fator diz respeito ao meio de divulgação da tradução, que, como sabemos, exerce uma influência direta nas estratégias adotadas pelo tradutor, visto que ele é submetido a um conjunto específico de regras postuladas por quem o contrata.

Quanto ao trabalho do tradutor, Britto (2012) ainda diz que ele deve ficar atento às estranhezas do texto e ser capaz de diferenciar quando esta aparição se trata na verdade de um recurso utilizado pelo autor na escritura de sua obra. Em casos como este, ele deve procurar respeitar essas particularidades e reproduzi-las tanto quanto seja possível no texto de chegada. Isso porque apesar de o tradutor ter tido sua visibilidade mais reconhecida nos últimos anos, ele não tem o direito de alterar propositalmente nem o conteúdo, nem a estilística do texto. Para finalizar sua discussão deste segundo capítulo, Britto (2012) ainda discorre sobre alguns problemas enfrentados pelo tradutor literário, como as diferenças entre duas línguas distintas e mesmo entre a língua falada e a língua escrita. Ele diz, por exemplo, que se a fala de determinado personagem possui "marcas de oralidade" (BRITTO, 2012, p.87), estas marcas devem aparecer no texto de chegada, pois são elas que conferem verossimilhança à fala do personagem. Ele ainda apresenta um breve estudo em que contrasta algumas diferenças entre português e inglês, através do qual o leitor de seu livro é conduzido a um exercício crítico sobre questões que envolvem a tradução de ficção.

No terceiro capítulo, "A tradução de poesia", o autor entra em um campo delicado em que encontramos partidários que defendem a intraduzibilidade do texto poético, outros que 
acreditam que é possível traduzir poesia, mas que a tradução resultante, na prática, é inevitavelmente falha, e os que acreditam na possibilidade de se traduzir poesia por saber que a poesia, assim como o texto ficcional, é um objeto estético. Esta última posição é a adotada por Paulo Henriques Britto.

Ao falar sobre a tradução do texto poético, Britto (2012, p. 120) coloca que "no poema, tudo, em princípio, pode ser significativo" e que caberá ao tradutor definir o que há de mais relevante no poema que deverá ser recriado na tradução. Essa colocação do autor retoma dois daqueles três princípios que expusemos no começo de nossa abordagem, o de haver a necessidade de se estabelecer uma classificação e o de se ter como objetivo a impossível meta de recriar no texto traduzido todas as marcas do texto de partida. E em se tratando da tradução de poesia, há para o autor uma diferença crucial entre esta e a tradução de prosa literária, que é o fato de que "na poesia os elementos da forma são de tal modo vitais que muitas vezes é mais neles que no plano do significado que reside a literariedade do texto" (BRITTO, 2012, p. 151) e que sendo assim, o tradutor de poesia deve se ater aos modos de significação do texto procurando recriá-los, ou buscar uma compensação para eles, em sua tradução.

O terceiro princípio, que retomamos agora, é aquele em que o autor expõe que mesmo que não haja uma certeza absoluta, "em nenhum ramo do conhecimento [...] não quer dizer que não podemos afirmar coisa alguma com o mínimo grau de segurança” (BRITTO, 2012, p. 29). Uma possível explicação para a compreensão deste princípio pode ser encontrada na análise comparativa entre duas traduções diferentes do mesmo poema que é exposta pelo autor neste terceiro capítulo. Passando em um primeiro momento por traduções feitas por Augusto de Campos e por Paulo Vizioli do fragmento de um poema de John Donne, Britto (2012) discorre sobre o trabalho feito por cada um deles em suas respectivas traduções e diz que a existência de argumentos razoáveis pode permitir que um crítico tenha meios para defender o seu ponto de vista ao dizer que determinada tradução é superior a outra. Em um segundo momento o autor apresenta fragmentos de suas próprias traduções e elucida uma série de procedimentos que guiaram suas escolhas tradutórias, demonstrando, de forma bastante didática, como um tradutor, ou mesmo um crítico, pode proceder para realizar uma tradução ou para avaliá-la, e que um trabalho cuidadoso e o estabelecimento de certos critérios facilitam este trabalho.

Para concluir a breve exposição sobre esta obra, gostaria de dizer que, além de ela ser de grande importância para o conhecimento de alguns dos pensamentos que norteiam os Estudos da Tradução nos dias de hoje, o fato de o autor exemplificar seus pensamentos 
permite ainda que o leitor tenha contato com um modelo fundamentado de crítica da tradução que o auxilia na construção de seu próprio horizonte.

${ }^{1}$ Currículo Lattes em: <http://buscatextual.cnpq.br/buscatextual/visualizacv.do?id=K4526361A0>. 